\title{
How does the self-reported health of undergraduate nursing students change during their degree programme? Survey results from a Scottish University
}

\author{
Josie M. M. Evans ${ }^{*}$ (D, Federico Andreis, Dawn M. Cameron and Claire E. Eades
}

\begin{abstract}
Background: The lifestyle behaviours, and the physical and mental health of nurses, are poorer than those of other allied health professionals, and of the general population. However, these were no less favourable among first year undergraduate nursing students at a Scottish Higher Education Institution (HEI) than among similar people of the same age. We compared health and health behaviours among the same cohort of undergraduate nursing students over the course of their degree.
\end{abstract}

Methods: An anonymous self-complete repeat cross-sectional survey was administered during a timetabled teaching session at three time-points to undergraduate nursing students at the start of Years 1, 2 and 3 of their programme. They had received written information about the study previously.

Results: Self-reported health did not change significantly over time, but there was a clear decline over the 3 years in the proportions of students rating their mental health as excellent/very good/good and a concomitant increase in those rating their mental health as fair/poor. Correspondingly, the mean WEMWBS wellbeing score declined over the 3 years, with the proportion of students with a score of $<46$ (indicating either high risk of major depression, or in high risk of psychological distress and increased risk of depression) increasing from one quarter to one half. This effect was captured and described using a Bayesian regression analysis. The most noticeable change in health behaviours was a decline in physical activity levels over the study period. The proportion of students managing 150 min of weekly physical activity decreased from three quarters to two thirds. This was reflected in higher selfreported sedentary time, although there were no observable trends over time in mean BMI, or proportions of students categorised as overweight or obese.

Conclusions: This paper suggests that there may be a decline in mental health and in participation in physical activity among nursing students over the course of their degree. We recommend the incorporation of an intervention into the undergraduate nursing curriculum that promotes and encourages regular physical activity, offering students the opportunity to learn about health promotion and lifestyle change in practice, to improve their own physical health, and to address mental wellbeing.

\footnotetext{
*Correspondence: josie.evans@stir.ac.uk

Faculty of Health Sciences and Sport, University of Stirling, Stirling, Scotland FK9 4LA, UK
} 


\section{Background}

Recent evidence suggests that the lifestyle behaviours, and the physical and mental health of nurses, are poorer than those of other allied health professionals, and even those of the general population [1]. However, we have shown that the health and health behaviours of first-year undergraduate nursing students at a Scottish Higher Education Institution (HEI) were no worse than those of similarly-aged respondents to the 2016 Scottish Health Survey [2]. But with the expanding health promotion role of nurses, it is important that they are credible role models to their patients, and a reasonable aspiration is that their health behaviour profile would be better than that of the general population. Their academic education surrounding health promotion, alongside exposure to the damaging health-related effects of poor lifestyle choices during clinical training, might result in improvement in the health behaviours of nursing students over time, but the academic and social demands of University life could conversely lead to a deterioration [3]. We have therefore continued to monitor the health and health behaviours of this cohort of undergraduate nursing students. The objective of this study was to compare these over time at three points during their programme.

\section{Methods}

Undergraduate nursing students (mental health and adult branch) at our Scottish HEI were given Participant Information Leaflets about our study, then a paperbased self-report questionnaire was administered to them by an academic member of staff during timetabled face-to-face teaching sessions at least $48 \mathrm{~h}$ later. This occurred on three occasions at the start of each academic year (September 2016, 2017 and 2018). The questionnaire contained seven sections relating to physical and mental health, and important health behaviours. It was adapted from sections of questionnaires used in several other HEIs [4], with additional questions informed by the Scottish Health Survey [5], and had a combination of open and semi-structured questions. Widely used measures of self-rated general health were also incorporated into the questionnaire [6], in that students were asked to rate separately their general physical and mental health as either excellent, very good, good, fair or poor. Emotional wellbeing was assessed using the WarwickEdinburgh mental wellbeing scale (WEMWBS). This provides a single score of between 14 and 70 , derived from a 14 item scale. It was developed and validated in student populations [7] and had test-retest reliability of 0.83 [8]. We asked students to report their weight and height in any units, then we converted units where necessary and calculated body mass index (BMI) as $\mathrm{kg} / \mathrm{m}^{2}$. A copy of the questions administered are presented in Appendix 1 (a supplemental file).
The students were asked not to give their name or any other information that would make them identifiable, although they generated their own, unique 12-digit alphanumeric identifier to add to the questionnaire for linkage purposes [2]. In this way, the results were anonymous. Students who chose not to complete the questionnaire were asked to return a blank form. Data were analysed descriptively using the SPSS v21.0 programme (Chicago, Illinois) and R 3.6.1 [9]. Subjects with missing data were excluded from the relevant analyses, and numerical variables were checked for outliers. Proportions were determined for categorical variables, and mean, median, standard deviation and range derived for continuous variables.

We used the 12-digit identifier to link together results from the same students at different time-points and identified those for whom data were available for all 3 years. We constructed three mixed effect regression models for three measures that warranted further investigation to determine whether there was an effect over time: whether the student was a current smoker or not (logistic regression), whether the student self-reported at least $150 \mathrm{~min}$ of physical activity per week (logistic regression), and the WEMWBS score (simple linear regression). Independent variables included age, gender, whether the student was the first in their family to go to university and year of degree programme (first, second or third). All regression models were fitted using the $R$ package rstanarm [10], and the usual convergence criteria were satisfied in all cases.

\section{Results}

There were 207 questionnaires returned by first year students in 2016, 175 by second years in 2017 and 103 by third years in 2018. Students were predominately female, with proportions of 86,73 and $84 \%$ each year respectively. Mean (median) ages were 24 (22) years, 25 (23) years and 27 (25) each year. From the numbers of student identified within each year group, the response rates were 88,81 and $52 \%$ respectively. Table 1 presents summary results (results for Year 1 have been published previously [2]).

In relation to physical health, a higher proportion of students in Year 3 (25.2\%) rated their health as excellent or very good compared to proportions within the two previous year groups (23.2\% in Year 1 and 18.3\% in Year 2 ). However, only $38.8 \%$ rated their health as good, compared to $48.3 \%$ in Year 1 and $49.1 \%$ in Year 2. A higher proportion in Year $3(34.9 \%)$ rated their health as fair/ poor, compared to $28.1 \%$ in Year 1 and $32.0 \%$ in Year 2.

This contrasted with results for mental health. There was a clear decline over the 3 years in the proportions of students rating their mental health as excellent/very good/good (from $48.3 \%$ in Year 1 to $26.2 \%$ in Year 3) 
Table 1 Summary results for health and health behaviour measures for a cohort of undergraduate nursing students in the first, second and third years of their degree programme

\begin{tabular}{|c|c|c|c|}
\hline & $\begin{array}{l}\text { Year } 1 \\
\text { (207 responses) } \\
\mathrm{n}(\%)\end{array}$ & $\begin{array}{l}\text { Year } 2 \\
\text { (175 responses) } \\
\mathrm{n}(\%)\end{array}$ & $\begin{array}{l}\text { Year } 3 \\
\text { (103 responses) } \\
n(\%)\end{array}$ \\
\hline \multicolumn{4}{|l|}{ General physical health } \\
\hline Excellent & $12(5.8)$ & $4(2.3)$ & $7(6.8)$ \\
\hline Very good & $36(17.4)$ & $28(16.0)$ & $19(18.4)$ \\
\hline Good & $100(48.3)$ & $86(49.1)$ & $40(38.8)$ \\
\hline Fair & $50(24.2)$ & $49(28.0)$ & $30(29.1)$ \\
\hline Poor & $8(3.9)$ & $7(4.0)$ & $6(5.8)$ \\
\hline Total & 206 & 174 & 102 \\
\hline \multicolumn{4}{|l|}{ Mental Health } \\
\hline Excellent & $19(9.2)$ & $12(6.9)$ & $6(5.8)$ \\
\hline Very good & $81(39.1)$ & $50(28.6)$ & $21(20.4)$ \\
\hline Good & $83(40.1)$ & $70(40.0)$ & $33(32.0)$ \\
\hline Fair & $19(9.2)$ & $29(16.6)$ & $34(33.0)$ \\
\hline Poor & $5(2.4)$ & $11(6.3)$ & $6(5.8)$ \\
\hline \multirow[t]{2}{*}{ Total } & 207 & 172 & 99 \\
\hline & $n=198$ & $n=173$ & $n=96$ \\
\hline WEMWBS score $<46$ & $48(24.2)$ & $60(34.7)$ & $49(51.0)$ \\
\hline Mean (median) WEMWBS score & $50.9(50.9)$ & $49.0(50.0)$ & $44.8(45.0)$ \\
\hline \multicolumn{4}{|l|}{ Physical activity } \\
\hline$\geq 150$ mins/week & $157(76.2)$ & $143(81.7)$ & $65(63.1)$ \\
\hline \multicolumn{4}{|l|}{ Mean (median) sedentary hours } \\
\hline Weekday & $6.0(6.0)$ & $6.1(6.0)$ & $8.9(8.0)$ \\
\hline Weekend & $6.4(6.0)$ & $6.2(5.5)$ & $8.0(8.0)$ \\
\hline \multicolumn{4}{|l|}{ Diet } \\
\hline Very healthy & $1(2.9)$ & $3(1.7)$ & $3(2.9)$ \\
\hline Healthy & $26(21.3)$ & $43(24.6)$ & $33(32.0)$ \\
\hline Average & $63(58.5)$ & $101(57.7)$ & $46(44.7)$ \\
\hline Unhealthy & 19 (15.9) & $26(14.9)$ & $21(20.4)$ \\
\hline Very unhealthy & $0(1.4)$ & $2(1.1)$ & - \\
\hline Total & 207 & 175 & 103 \\
\hline Breakfast most days & $142(68.9)$ & $108(61.7)$ & $56(54.4)$ \\
\hline$\geq 5$ fruit/veg per day & $25(12.1)$ & $22(12.6)$ & $15(14.6)$ \\
\hline Takeaway at least once/week & $88(42.7)$ & $75(42.9)$ & $41(39.8)$ \\
\hline BMI & $n=165$ & $n=133$ & $n=84$ \\
\hline Mean (median) & $25.2(24.1)$ & $24.8(24.1)$ & $25.4(24.2)$ \\
\hline BMI 25-30 & $48(29.0 \%)$ & $37(27.8 \%)$ & $22(26.1 \%)$ \\
\hline (overweight) BMI $\geq 30$ (obese) & $30(18.2)$ & $19(14.3)$ & $16(19.0)$ \\
\hline \multicolumn{4}{|l|}{ Sleep } \\
\hline Very well & $35(16.9)$ & $33(18.9)$ & $19(18.4)$ \\
\hline Well & $71(34.3)$ & $43(24.6)$ & $27(26.2)$ \\
\hline Average & 79 (38.2) & $70(40.0)$ & 39 (37.9) \\
\hline Badly & $21(10.1)$ & $23(13.1)$ & 14 (13.6) \\
\hline Very badly & $1(0.5)$ & $6(3.4)$ & $4(3.9)$ \\
\hline
\end{tabular}


Table 1 Summary results for health and health behaviour measures for a cohort of undergraduate nursing students in the first, second and third years of their degree programme (Continued)

\begin{tabular}{|c|c|c|c|}
\hline & $\begin{array}{l}\text { Year } 1 \\
\text { (207 responses) } \\
\mathrm{n}(\%)\end{array}$ & $\begin{array}{l}\text { Year } 2 \\
\text { (175 responses) } \\
n(\%)\end{array}$ & $\begin{array}{l}\text { Year } 3 \\
\text { (103 responses) } \\
n(\%)\end{array}$ \\
\hline Total & 207 & 175 & 103 \\
\hline$<7$ h sleep/night & $70(34.0)$ & $63(36.0)$ & $44(42.7)$ \\
\hline Mobile device $>30$ mins & $129(62.3)$ & $99(56.6)$ & $66(64.1)$ \\
\hline Alcohol & $n=204$ & $n=173$ & $n=100$ \\
\hline Consumes any alcohol & $186(92.1)$ & $154(89.0)$ & $86(86.0)$ \\
\hline \multicolumn{4}{|l|}{ Drinks alcohol } \\
\hline occasionally/never & $134(65.7)$ & $115(66.5)$ & $78(78.0)$ \\
\hline Drinks $\geq 14$ units/wk & $12(5.9)$ & $16(9.2)$ & $3(3.0)$ \\
\hline Weekly binge drinking & $32(15.7)$ & $35(20.2)$ & $15(15.0)$ \\
\hline \multicolumn{4}{|l|}{ Smoking } \\
\hline Daily & $32(15.8)$ & $16(9.1)$ & $9(8.7)$ \\
\hline$<$ daily & $18(8.9)$ & $22(12.6)$ & $11(10.7)$ \\
\hline
\end{tabular}

and a concomitant increase in those rating their mental health as fair/poor (from $11.6 \%$ in Year 1 to $38.8 \%$ in Year 3). This result was backed up by the results of the WEMWBS score. Not only did the mean score decline from 50.9 to 44.8 over the 3 years, but the proportion of students with a WEMWBS score of $<46$ (indicating either high risk of major depression, or in high risk of psychological distress and increased risk of depression) increased from 24.1\% in Year 1 to $51.0 \%$ in Year 3.

Health behaviours were also investigated. Physical activity levels declined over the study period, with the proportion of students managing $150 \mathrm{~min}$ of physical activity per week decreasing from $76.2 \%$ in Year 1 to $63.1 \%$ in Year 3. This was reflected in higher selfreported sedentary time. The results for dietary behaviour were less clear cut. Fewer students over time reported their diets as average $(58.5 \%$ in Year 1 compared with $44.7 \%$ in Year 3), with higher proportions over time rating their diets as either healthy or very healthy, or as unhealthy or very unhealthy. There was a decrease in the proportion of students eating breakfast most days, from $68.9 \%$ in Year 1 to $54.4 \%$ in Year 3 (but no difference for consumption of fruit and vegetables, and takeaways). However, there were no clear differences over time in mean BMI, or proportions of students with a BMI categorising them as overweight or obese.

There was a small increase over time in the proportions of students who reported sleeping poorly or very poorly (from $10.6 \%$ in Year 1 to $17.5 \%$ in Year 3), and there were higher proportions of students who reported sleeping for less than seven hours per night (from 34.0\% in Year 1 to $42.7 \%$ in Year 3). There was evidence of a possible decline in alcohol consumption over time, with any alcohol consumption declining from $92.1 \%$ in Year 1 to $86.0 \%$ in Year 3, and an increasing proportion of students drinking alcohol only occasionally or never. Binge drinking appeared to peak in Year 2. The proportion of students smoking (current or occasional) decreased from 24.7 to $19.4 \%$ over the course. The decline was most marked for current smokers; whereas occasional smoking was higher in Year 2, perhaps indicating that some smokers were cutting down and moving from daily to occasional smoking.

We identified 51 students for whom data was available for all three time-points. The results of the regression analyses, using a Bayesian approach, are presented in Table 2. They suggest a clear effect of worsening WEMWBS score over time, but no effect for smoking or physical activity behaviour. The other notable result was that males had poorer WEMWBS scores. However, among this sub-sample of 51 students, the proportion of smokers (15\%) was lower, and the proportion achieving 150 min of physical activity (84\%) was higher than in the overall sample during the first year. In contrast, their mean WEMWBS score as baseline was very similar to that of the overall cohort.

\section{Discussion}

Among a cohort of undergraduate nurses who commenced their nursing training at a HEI in Scotland, a clear picture emerges of students experiencing deteriorating mental health over the course of their degree, and a decline in physical activity. Results for other health behaviours and associated outcomes were less clear cut, although alcohol consumption and smoking declined over the study period. Perhaps the most concerning result are the high proportions of students, increasing steadily over the course of the programme, self-reporting poor or very 
Table 2 Mean, standard deviation, 10th, 50th, and 90th percentiles of the posterior distribution of the parameters estimates for the three regression models, constructed for 51 students for whom data were available at all three time-points

\begin{tabular}{|c|c|c|c|c|c|}
\hline & Mean & Standard deviation & $10 \%$ & $50 \%$ & $90 \%$ \\
\hline \multicolumn{6}{|l|}{ Dependent variable: Non-smoking } \\
\hline Age & 0.1 & 0.2 & -0.2 & 0.1 & 0.3 \\
\hline Not female $v$ female & -1.6 & 2.3 & -4.5 & -1.6 & 1.3 \\
\hline Not first gen. Uni $v$ first gen. Uni & 1.7 & 1.8 & -0.8 & 1.7 & 4.0 \\
\hline Year 2 v Year 1 & 0.0 & 0.3 & -0.4 & 0.0 & 0.4 \\
\hline Year $3 v$ Year 1 & 0.0 & 0.3 & -0.4 & 0.0 & 0.4 \\
\hline \multicolumn{6}{|c|}{ Dependent variable: Self-reporting $150 \mathrm{~min}$ of PA per week } \\
\hline Age & 0.1 & 0.2 & -0.3 & 0.1 & 0.1 \\
\hline Not female $v$ female & -0.3 & 2.0 & -2.9 & -0.3 & 2.3 \\
\hline Not first gen Uni $v$ first gen. Uni & 0.1 & 1.6 & -1.9 & 0.1 & 2.1 \\
\hline Year $2 v$ Year 1 & 0.0 & 0.2 & -0.3 & 0.0 & 0.3 \\
\hline Year $3 v$ Year 1 & 0.0 & 0.2 & -0.3 & 0,0 & 0.3 \\
\hline \multicolumn{6}{|l|}{ Dependent variable: WEMWBS score } \\
\hline Age & 0.2 & 0.2 & -0.1 & 0.2 & 0.5 \\
\hline Not female $v$ female & -6.4 & 4.6 & -12.4 & -6.4 & -0.4 \\
\hline Not first gen. Uni $v$ first gen. Uni & 1.5 & 2.8 & -2.2 & 1.4 & 5.0 \\
\hline Year $2 v$ Year 1 & -2.6 & 0.4 & -3.1 & -2.6 & -2.1 \\
\hline Year $3 \vee$ Year 1 & -7.0 & 0.3 & -7.5 & -7.0 & -6.6 \\
\hline
\end{tabular}

poor mental health. By the beginning of their third year, half of all students had a WEMWBS score indicative of a risk or high risk of major depression, or high risk of psychological distress. While, it could be that the survey was administered at a particularly stressful point in the programme, the clear trend over time belies this. The results of a linear regression analysis among a subgroup of 51 students confirm that the data are consistent with a real effect over time. There may therefore be a need for more targeted monitoring and support for the mental health of undergraduate nursing students. This is an international concern, and has prompted a study following up stress among nursing students in the US as they transition to their first job [11]. Potential poor psychological health among the nursing workforce is extremely worrying, given that they are likely to have longer careers than their predecessors, and require psychological capacity and resilience to provide high standards of nursing care.

The other health behaviour measure for which there was some evidence of significant worsening over time in the cross-sectional results was physical activity, but this was not evident among the subgroup of 51 students for whom data were available at all three time-points. Neither was it reflected in results for BMI, although there were unlikely to be substantial changes within the limited time frame of this study. Despite this, the current level of overweight/obesity among nurses in Scotland is $69 \%$ [12] and it is worrying that a decline in physical activity is already evident among students before they have even left further education. Other studies among nursing students in the US [13], Spain and Colombia [14], Hong Kong [15] and Thailand [16] have also found the majority of students not meeting physical activity guidelines. We have carried out qualitative research among second year student nurses who report that they find it increasingly difficult to build physical activity into their daily lives, given the time pressures of studying, working and attending clinical placements.

Interestingly, there were some positive results such as a decline in smoking, with a suggestion that some daily smokers may have been reducing smoking frequency. While this was not evident among the sub-group of 51 students, in a separate (as yet unpublished) study some referred to the striking impact of observing the direct effects of smoking in clinical practice which may be a cue for action to behaviour change. This is important as meta-analysis indicates that smoking in nursing students is high worldwide [17]. However, in a study in Spain and Portugal the proportions of students smoking increased with each successive year [18]. Further research is needed on how to reverse this trend.

This study relied upon the use of a self-report questionnaire, the limitation being that the accuracy of student responses cannot be guaranteed. Student responses may have been influenced by social desirability bias, and/or by an increased awareness of the importance of health behaviours as a result of their undergraduate 
training. Many of the questions categorised respondents into relatively wide categories, although the survey was intended to identify broad areas of concern warranting further investigation or intervention, for which very sensitive measures were not necessarily required. One weakness of the study was the lower response rate among third year students. The survey was administered during a timetabled session. Either student turn-out was particularly low for this session, or many students decided not to return their questionnaire. The question is whether non-response was associated with poorer selfrated health or health behaviours; in which case we might expect students in better health to be more likely to attend class and therefore observe improved health among the third year group; this did not appear to be the case. Although we identified 51 students for whom data were available at three time-points, patterns observed in cross-sectional analyses were not observed in this smaller sub-group for smoking and physical activity. It is important to note though that their health behaviours in Year 1 appeared more favourable than in the entire cohort, so they may not be representative of the entire cohort for health behaviours. In contrast, in their first year, their mean WEMWBS score (indicative of mental wellbeing), was similar to that of the overall cohort.

Our study has identified an important overall trend of declining mental health among undergraduate nursing students over time. Given the substantial body of evidence indicating that physical activity improves mental wellbeing $[19,20]$, it is likely that they would benefit from increased levels of physical activity.

\section{Conclusions}

We recommend the incorporation of an intervention into the undergraduate nursing curriculum that promotes and encourages regular physical activity. This could offer students the opportunity to learn about health promotion and lifestyle change in practice to improve their own physical health, and to address mental wellbeing. With the increasing role nurses play in health promotion and calls for them to act as healthy role models for patients, it is vital that nursing students are supported to improve their own health from the beginning of their training.

\footnotetext{
Abbreviations

HEl: Higher Education Institution; WEMWBS: Warwick-Edinburgh Mental Wellbeing Scale; BMI: Body Mass Index
}

\section{Supplementary Information}

The online version contains supplementary material available at https://doi. org/10.1186/s12912-021-00563-w.

Additional file 1. Copy of administered questionnaire.

\section{Acknowledgements}

Not applicable.

\section{Authors' contributions}

$J E, D C$ and CE conceived the study, designed the questionnaire and supervised data collection. JE carried out preliminary analysis of the data and wrote the first draft of the manuscript. FA conducted the Bayesian analyses. All authors contributed to the final manuscript, and read and approved the final version.

\section{Funding}

There was no specific funding for this study.

\section{Availability of data and materials}

The datasets used and/or analysed during the current study are available from the corresponding author on reasonable request.

\section{Declarations}

\section{Ethics approval and consent to participate}

Ethical approval for the study was granted by the University of Stirling School of Health Sciences Research Ethics Committee in July 2016 (reference 15/16:67), with amendments for subsequent year groups in 2017 and 2018. Receipt of a completed questionnaire was used as a written indication of consent to participate.

\section{Consent for publication}

Not applicable.

\section{Competing interests}

None declared.

Received: 23 January 2020 Accepted: 8 March 2021

Published online: 17 March 2021

\section{References}

1. Scottish Government (2017). Nursing 2030 Vision: Promoting confident, competent and collaborative nursing for Scotland's future.

2. Evans JMM, Eades CE, Cameron DM. Health and health behaviours among a cohort of first year nursing students in Scotland: a self-report survey. Nurse Educ Pract. 2019;36:71-5. https://doi.org/10.1016/j.nepr.2019.02.019.

3. Bryer J, Cherkis F. Raman. Health-promotion behaviours of undergraduate nursing students: A survey analysis. Nurs Educ Perspect. 2013;34(6):410-5, Health-Promotion Behaviors of Undergraduate Nursing Students: A Survey Analysis. https://doi.org/10.5480/11-614

4. Deniozou T (2015). Student health and lifestyle survey. Healthy University project. University of Edinburgh. https://www.ed.ac.uk/files/atoms/files//hea Ithy_university_research_report_final_july_15.pdf.Accessed 11/1/2018).

5. Scottish Government (2016). Scottish Health Survey 2016. Volume 1: Main Report. http://www.gov.scot/Publications/2017/10/2970/downloads\#res-1 Accessed 16/1/2018.

6. Bombak AE. Self-rated health and public health: a critical perspective. Front Public Health. 2013;1:15.

7. Warwick Medical School (2018). Uses of WEMWBS. https://warwick.ac.uk/fac/ med/research/platform/wemwbs/researchers/uses/Accessed 17/1/2018.

8. Tennant R, Hiller L, Fishwick R, Platt S, Joseph S, Weich S, Parkinson J, Secker J, Stewart-Brown S. The Warwick-Edinburgh mental well-being scale (WEMWBS): development and UK validation. Health Qual Life Outcomes. 2007;5(1):63. https://doi.org/10.1186/1477-7525-5-63.

9. Core Team R. R: a language and environment for statistical computing. Vienna: R Foundation for statistical computing; 2019. URL https://www.Rproject.org/

10. Goodrich B, Gabry J, Ali I, Brilleman S. (2018). Rstanarm: Bayesian applied regression modeling via Stan. R package version 2.17.4. http://mc-stan.org/.

11. Olvera Alvarez H, Provencia-Vasquez E, Slavich GM, Laurent JGC, Browning M, McKee-Lopez G, Robbins L, Spengler JD. Stress and health in nursing students. The nurse engagement and wellness study. Nurs Res. 2019;68(6): 453-63. https://doi.org/10.1097/NNR.0000000000000383.

12. Kyle RG, Neall RA, Atherton IM). Prevalence of overweight and obesity among nurses in Scotland: a cross-sectional study using the Scottish health 
survey. Int J Nurs Stud 2016; 53:126-133, DOI: https://doi.org/10.1016/j. ijnurstu.2015.10.015.

13. Fitzgerald LZ. Categorization and determinants of physical activity among nursing students. J Nurs Educ Pract. 2015;5:10-20.

14. Rodriguez-Gasquez M, Chaparro-Hernandez S, Gonzalez-Lopez JR. Are first year students' lifestyles coherent with their future career? Int J Nurs Pract. 2017;23:e12511.

15. Choi-Hui WH. The health-promoting lifestyles of undergraduate nurses in Hong Kong. J Prof Nursing. 2012;18:101-11.

16. Klainin-Yobas $\mathrm{P}, \mathrm{He} \mathrm{H}-\mathrm{G}$, Lau Y. Physical fitness, health behaviour and health among nursing students: a descriptive correlational study. Nurse Educ Today. 2015;35(12):1 199-205. https://doi.org/10.1016/j.nedt.2015.06.014.

17. Zeng L-N, Zong Q-Q, Zhang J-W, An F-R, Xiang Y, Ng CH, Ungvari GS, Yang F-Y, Yan H, Chen LHX, Xiang Y-T. Prevalence of smoking in nursing students worldwide: a meta-analysis of observational studies. Nurse Educ Today. 2020;84:104205. https://doi.org/10.1016/j.nedt.2019.104205.

18. Fernandez-Garcia D, Ordas B, Fernandez-Pena R, Barcena-Calvo B, Ordonez C, Amo-Setien FJ, Gomez-Slagado J, Martinez-lsasi S. Smoking in nursing students. A prevalence multi-center study. Medicine. 2020;14:e19414.

19. Mammen G, Faulkner G. Physical activity and the prevention of depression: a systematic review of prospective studies. Am J Prev Med. 2013;45(5):64957. https://doi.org/10.1016/j.amepre.2013.08.001.

20. Rosenbaum S, Tiedermamm A, Sherrington C, Curtis J, Ward PB. Physical activity interventions for people with mental illness: a systematic review and meta-analysis. Psychiatrist. 2014;75(9):964-74.

\section{Publisher's Note}

Springer Nature remains neutral with regard to jurisdictional claims in published maps and institutional affiliations.

Ready to submit your research? Choose BMC and benefit from:

- fast, convenient online submission

- thorough peer review by experienced researchers in your field

- rapid publication on acceptance

- support for research data, including large and complex data types

- gold Open Access which fosters wider collaboration and increased citations

- maximum visibility for your research: over $100 \mathrm{M}$ website views per year

At $\mathrm{BMC}$, research is always in progress.

Learn more biomedcentral.com/submissions 